Pesq. Vet. Bras. 37(8):785-789, agosto 2017 DOI: $10.1590 / \mathrm{S} 0100-736 \mathrm{X} 2017000800001$

\title{
Intoxicação por Portulaca elatior (Portulacaceae) em bovinos ${ }^{1}$
}

\author{
Temístocles Soares de Oliveira Neto ${ }^{2}$, Franklin Riet-Correa ${ }^{3}$, Francisca Maria Sousa \\ Barbosa ${ }^{4}$, Harlan Hallamys Lima Nascimento ${ }^{4}$, Lucas Rannier Ribeiro Antonino \\ Carvalho ${ }^{4}$, Alexandre José Alves ${ }^{5}$ e Ricardo Barbosa Lucena ${ }^{4 *}$
}

\begin{abstract}
Oliveira Neto T.S., Riet-Correa F., Barbosa F.M.S., Nascimento H.H.L., Carvalho L.R.R.A., Alves A.J. \& Lucena R.B. 2017. [Portulaca elatior (Portulacaceae) poisoning in cattle.] Intoxicação por Portulaca elatior (Portulacaceae) em bovinos. Pesquisa Veterinária Brasileira 37(8):785-789. Departamento de Ciências Veterinárias, Laboratório de Patologia Veterinária, Universidade Federal da Paraíba, Centro de Ciências Agrárias, Campus II, Areia, PB 58397-000. E-mail: lucena.rb@gmail.com

An outbreak of acute poisoning in cattle caused by the ingestion of Portulaca elatior occurred in the northeastern Brazil. The outbreak resulted from ingestion of the plant provided by the farmer. Four out of five cattle were poisoned and two died. Clinical signs included abdominal pain, muscle trembling, intense salivation, mild bloat and dehydration. The course of the disease ranged from 10 to 18 hours. Gross findings included dehydration, reddening of the mucosa of forestomachs, abomasum, and intestine, with ulcerations of the ruminal mucosa. The presence of Portulaca leaves in the rumen was noted in both cases. The main histologic lesions were superficial to full thickness degeneration and necrosis of the stratified epithelium lining the forestomachs, necrosis and inflammation of the intestinal mucosa, and lymphoid necrosis. The serum activities of AST and GGT and serum were within normal ranges. The diagnosis of poisoning associated with ingestion of $P$. elatior was based on the epidemiology, clinical signs and lesions. The lack of information about the toxicity of P. elatior was the main cause for the accident of poisoning.
\end{abstract}

INDEX TERMS: Poisonous plants, Portulaca elatior, Portulacaceae, plant poisoning, disease of cattle, rumen, necrosis.

RESUMO.- Descreve-se um surto de intoxicação aguda em bovinos causado pela ingestão de Portulaca elatior na região nordeste do Brasil. 0 surto resultou da ingestão a partir da administração da planta no cocho pelo criador para

\footnotetext{
${ }^{1}$ Recebido em 13 de agosto de 2015.

Aceito para publicação em 21 de julho de 2016

Parte da Tese de Doutorado do primeiro autor.

${ }^{2}$ Programa de Pós-Graduação em Medicina Veterinária, Universidade Federal de Campina Grande (UFCG), Centro de Saúde e Tecnologia Rural (CSTR), Avenida Universitária s/n, Bairro Santa Cecília, Patos, PB 58708110, Brasil. E-mail: temivet@hotmail.com

${ }^{3}$ Instituto Nacional de Investigación Agropecuaria (INIA), La Estanzuela, Colonia, Uruguay. E-mail: franklin.riet@pq.cnpq.br

${ }^{4}$ Laboratório de Patologia Veterinária, Departamento de Ciências Veterinárias, Universidade Federal da Paraíba (UFPB), Centro de Ciências Agrárias (CCA), Campus II, Areia, PB 58397-000, Brasil. E-mails: franciscaaraguaia@gmail.com, harlanhallamys@gmail.com, lucasrveter@gmail. com; *Autor para correspondência: lucena.rb@gmail.com

${ }^{5}$ Laboratório de Medicina Veterinária Preventiva, Departamento de Ciências Veterinárias, CCA-UFPB, Campus II, Areia, PB 58397-000, Brasil. E-mail: alexandrealves@cca.ufpb.br
}

os bovinos. Quatro de cinco bovinos foram intoxicados e dois morreram. Os sinais clínicos incluíram dor abdominal, tremores musculares, intensa salivação, timpanismo moderado e desidratação. 0 curso clínico da doença variou de 10 a 18 horas. Os achados macroscópicos incluíram desidratação, avermelhamento das mucosas dos pré-estômagos, abomaso e intestinos, além de ulceração da mucosa ruminal. Nos dois casos foi notada a presença de fragmentos de Portulaca no interior do rúmen. Os achados histológicos foram de degeneração e necrose das camadas superficiais do epitélio dos pré-estômagos, necrose e inflamação da mucosa intestinal e necrose linfoide. As atividades de AST e GGT estavam dentro dos valores de normalidade. 0 diagnóstico de intoxicação associado à ingestão de P. elatior foi baseado na epidemiologia, sinais clínicos e lesões. A ausência de informação sobre a toxicidade de P. elatior foi a principal causa para a ocorrência da intoxicação acidental.

TERMOS DE INDEXAÇÃO: Plantas tóxicas, Portulaca elatior, Portulacaceae, doenças de bovinos, intoxicação por plantas, rúmen, necrose. 


\section{INTRODUÇÃO}

0 gênero Portulaca L. (Portulacaceae) inclui aproximadamente 115 espécies de plantas herbáceas (Eggli \& Ford-Werntz 2002), carnosas, anuais ou perenes, com folhas alternadas, distribuídas principalmente na América do Norte, América do Sul e África (Coelho \& Giulietti 2010). No Brasil estima-se que há 21 espécies de Portulaca, encontradas principalmente na Região Nordeste (Legrand 1962). Dentre as várias espécies, apenas Portulaca oleracea e $P$. elatior foram descritas como tóxicas para ovinos e caprinos, respectivamente (Galiza et al. 2011, Simões 2013). No município de São José do Egito, semiárido de Pernambuco, a espécie Portulaca oleracea foi suspeitada como causa de intoxicação em ovinos. A planta foi fornecida no curral para 20 ovinos e após duas horas todos os animais desenvolveram fraqueza, timpanismo, polaquiúria, decúbito e morte de oito ovinos. Para determinar a toxicidade, a planta foi administrada a sete ovinos na dose de $80 \mathrm{~g} / \mathrm{kg}$, resultando na intoxicação de todos ovinos entre uma e quatro horas após a ingestão, com sinais clínicos semelhantes aos descritos no surto espontâneo. Cinco animais se recuperaram, incluindo um que recebeu o tratamento com azul de metileno, e dois morreram. Na necropsia as mucosas estavam cianóticas e o sangue marrom. 0 estudo concluiu que a presença de nitratos e nitritos nesta espécie de Portulaca foi responsável pela intoxicação nos ovinos (Simões 2013).

No Agreste do estado da Paraíba, município de Aroeiras, a espécie Portulaca elatior foi responsável por um surto de intoxicação, caracterizado por distúrbios gastrointestinais em um rebanho caprino. Foram acometidos caprinos criados em uma área livre de P. elatior e posteriormente transferidos para um pasto altamente infestado pela planta, sugerindo que o desconhecimento dessa planta por caprinos predispõe a ocorrência de surtos de intoxicação. A doença foi comprovada experimentalmente nos caprinos pela ingestão das doses de 10, 20 e 40 gramas da planta fresca por $\mathrm{kg}$ de peso animal (g/kg) (Galiza et al. 2011). Produtores rurais do semiárido do Rio Grande do Norte relatam que $P$. elatior é responsável por quadro de timpanismo em bovinos (Silva et al. 2006). Porém, não são encontrados na literatura relatos confirmados e detalhados de intoxicação por P. elatior em bovinos. 0 presente trabalho tem como objetivos descrever os aspectos epidemiológicos, clínicos e patológicos de um surto de intoxicação por P. elatior em bovinos.

\section{MATERIAL E MÉTODOS}

As avaliações epidemiológicas, clínicas e as necropsias foram realizadas a partir de visita a uma propriedade com histórico de doença aguda em bovinos no município de Gado Bravo, estado da Paraíba, Brasil. 0 município de Gado Bravo (07³5’ 00” de latitude sul e $35^{\circ} 47^{\prime} 27^{\prime \prime}$ de longitude oeste) está localizado na Mesorregião Agreste Paraibano, de clima semiárido seco e muito quente, com apenas duas estações bem definidas, estação chuvosa de março a setembro, e seca o restante do ano (CPRM 2005).

Os históricos clínicos de quatro bovinos intoxicados da ingestão acidental a partir da administração da planta pelo criador para os bovinos, foram obtidos em entrevistas com o proprietário e o médico veterinário que atendeu os animais anteriormente.
Durante a visita foram encontradas uma vaca morta, uma bezerra em decúbito lateral e uma bezerra e uma vaca em fase de recuperação. Foram coletadas amostras de sangue da bezerra doente para realização de hemograma e determinação das atividades séricas de aspartato-amino transferase (AST) e gama-glutamil transferase (GGT).

Amostras de uma planta herbácea que havia sido fornecida para os bovinos foram enviadas para o Laboratório de Botânica da Universidade Federal da Paraíba para identificação botânica e tombamento; foi identificado como sendo Portulaca elatior, da família Protulacaceae.

Foram submetidos à necropsia dois bovinos que morreram naturalmente, a vaca encontrada morta e a bezerra que morreu espontaneamente duas horas após o exame clínico. Fragmentos de todos os órgãos internos e pele, encéfalo e medula espinhal foram coletados, fixados em formol $10 \%$, processados rotineiramente, incluídos em parafina, cortados a $4 \mu \mathrm{m}$, corados com hematoxilina e eosina (HE), seguido de exame histopatológico.

\section{RESULTADOS}

O surto de intoxicação por Portulaca elateor ocorreu no início de abril de 2015. Durante os seis meses anteriores ao surto, devido à prolongada estiagem no município de Gado Bravo, havia pouca disponibilidade de pasto na propriedade e ao longo desse período o proprietário estava fornecendo no cocho palma forrageira a cinco bovinos (duas vacas em lactação, uma vaca seca e duas bezerras desmamadas, com seis meses de idade). Após as primeiras chuvas da estação que ocorreram no final de março, uma planta infestante brotou em meio à plantação de palma (Fig.1). 0 proprietário colheu aproximadamente $30 \mathrm{~kg}$ desta planta e forneceu ainda fresca aos animais, que estavam há 10 horas confinados e em jejum no curral.

Adoeceram quatro bovinos (duas vacas e duas bezerras) e morreram dois (uma vaca e uma bezerra). Os sinais clínicos iniciaram aproximadamente 10 horas após a ingestão da planta em uma vaca, 12 horas em duas bezerras e

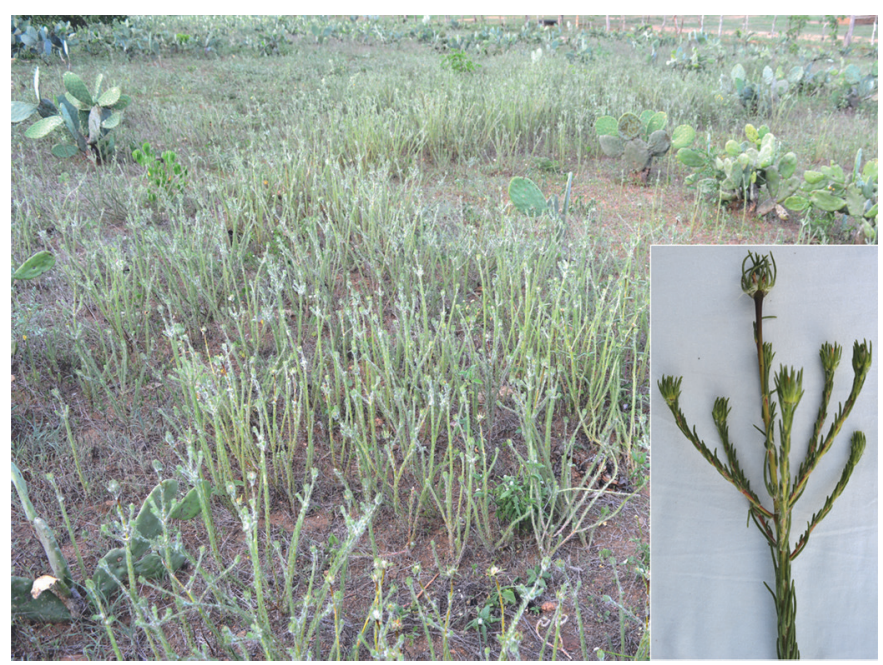

Fig.1. Cultivo de palma forrageira intensamente invadida por Portulaca elatior, município de Gado Bravo, Paraíba. No detalhe aproximado notar a planta com flores. 0 proprietário colheu aproximadamente $30 \mathrm{~kg}$ desta planta herbácea e a forneceu ainda fresca aos bovinos, que estavam há 10 horas confinados e em jejum no curral. 
20 horas em outra vaca. A vaca e a bezerra que morreram naturalmente apresentaram inicialmente contrações abdominais, seguidas por tremores do corpo, cabeça e lábios, incoordenação, quedas, decúbito esternal, com posterior decúbito lateral com intensa salivação, desidratação e morte 10 horas e 18 horas, respectivamente, após o início dos sinais clínicos. Outra bezerra apresentou apatia, incoordenação e tremores do corpo e cabeça e recuperou-se após 12 horas. Uma vaca apresentou apatia e perda do apetite e recuperou-se 10 horas após o início dos sinais clínicos. Outra vaca que consumiu pouca quantidade da planta não apresentou alterações clínicas. Dois bezerros lactentes, com um mês de idade, filhos destas duas últimas vacas não apresentaram nenhuma alteração. Todos os bovinos com quadro de intoxicação foram tratados com fluidoterapia intravenosa. Não foram observadas alterações no hemograma e atividades séricas de AST e GGT.

Os achados macroscópicos nos dois bovinos submetidos à necropsia caracterizaram-se por acentuada desidratação do cadáver e marcada distensão dos pré-estômagos por abundante conteúdo líquido e fragmentos vegetais semelhantes à planta fornecida no cocho. As mucosas do rúmen, retículo e omaso estavam difusamente avermelhadas, com extensas áreas de desprendimento epitelial (Fig.2). A submucosa adjacente às áreas ulceradas demonstrava acentuada hiperemia. As pregas da mucosa do abomaso de ambos os bovinos estavam edematosas. 0 intestino delgado estava preenchido por fluído com mucosa marcadamente congesta. Os pulmões estavam distendidos por grande quantidade de fluído aquoso (edema).

As principais alterações microscópicas foram encontradas nos pré-estômagos, abomaso, intestino delgado, linfonodos e agregados linfoides. As células epiteliais dos pré-estômagos demonstravam citoplasma vacuolizado (Fig. 3). Em algumas áreas essas células apresentavam necrose de coagulação, principalmente das porções mais basais, resultando em desprendimento epitelial, que por sua vez, formavam fendas entre a mucosa e a submucosa, preen-

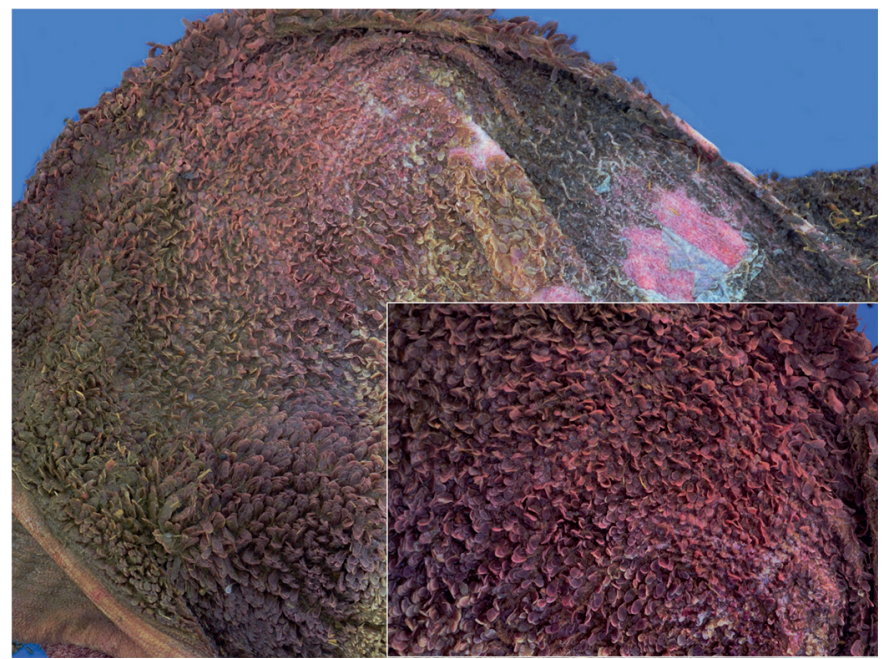

Fig.2. Difuso avermelhamento e desprendimento da mucosa do rúmen em um bovino naturalmente intoxicado por Portulaca elatior no município de Gado Bravo, Paraíba. No detalhe aproximado notar o intenso avermelhamento das papilas ruminais.

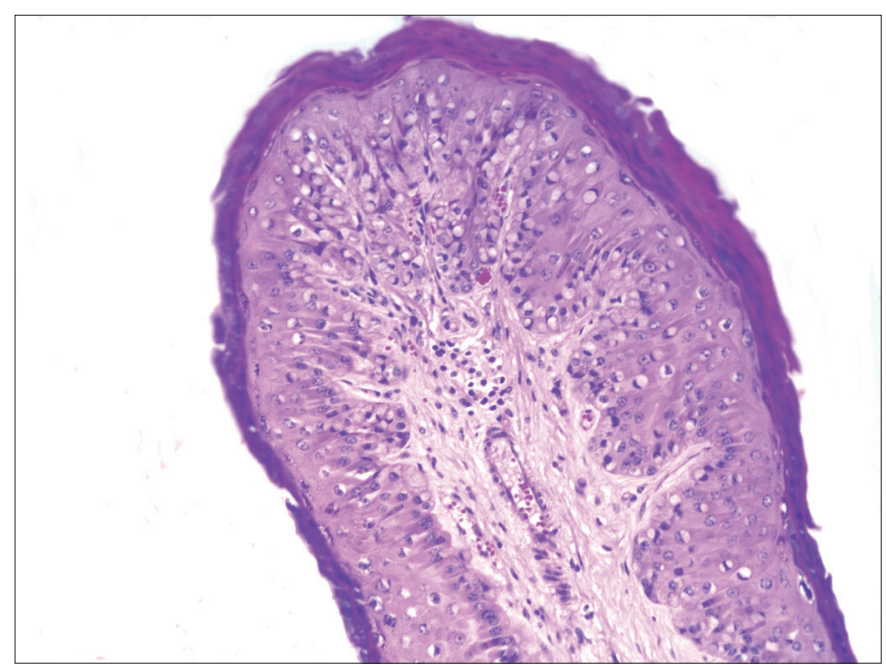

Fig.3. Mucosa do rúmen de um bovino naturalmente intoxicado por Portulaca elatior no município de Gado Bravo, Paraíba. Note a vacuolização das células do epitélio estratificado do rúmen e infiltrado inflamatório linfoplasmocitário na submucosa. HE, obj.20x.

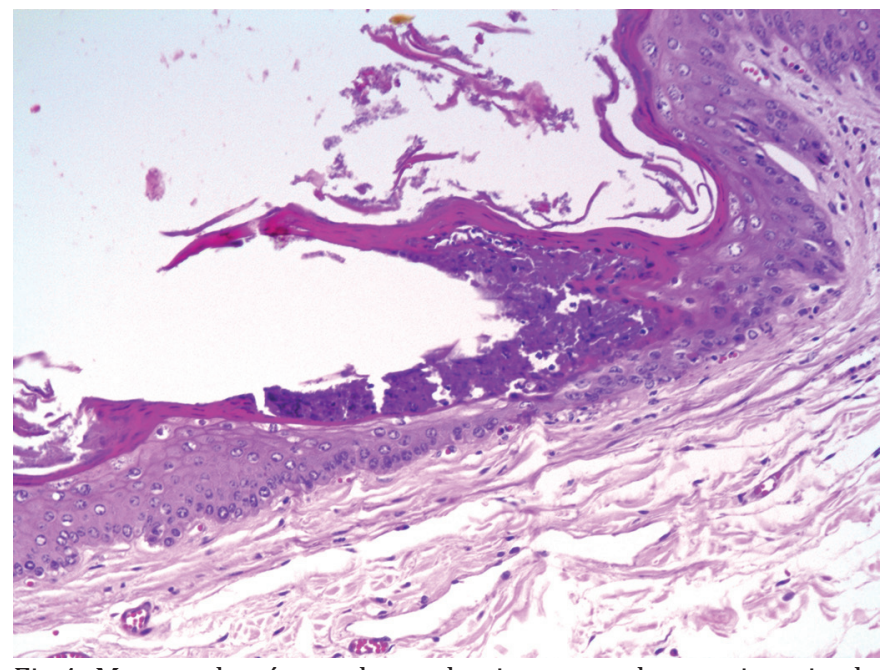

Fig.4. Mucosa do rúmen de um bovino naturalmente intoxicado por Portulaca elatior no município de Gado Bravo, Paraíba. Note a necrose afetando o epitélio estratificado do rúmen. Agregados basofílicos (bactérias) podem ser observados pavimentando a superfície epitelial necrótica. HE, obj.40x.

chidas por restos celulares e fibrina. Em alguns segmentos as células do epitélio estratificado estavam completamente desprendidas, formando úlceras focalmente extensas. Miríades de agregados bacterianos foram observadas na superfície dessas áreas (Fig.4). A submucosa adjacente estava marcadamente hiperêmica, edematosa e infiltrada por neutrófilos. No abomaso e intestino foram observadas áreas de necrose epitelial, além de edema e hiperemia. $\mathrm{Na}$ submucosa dos pré-estômagos e na mucosa do abomaso e intestino delgado havia também infiltração de linfócitos e plasmócitos. Os linfonodos mesentéricos e o tecido linfoide associado às mucosas (MALT) apresentavam necrose dos linfócitos dos centros germinativos secundários, caracterizada pela presença de núcleos picnóticos e cariorréticos nestas áreas (Fig.5). 


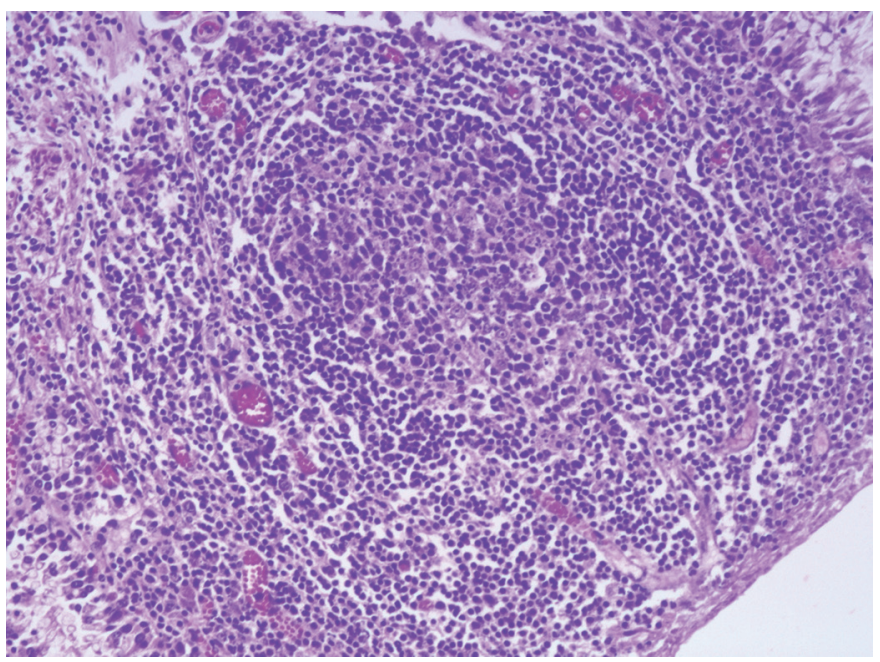

Fig.5. Agregado linfoide de um bovino naturalmente intoxicado por Portulaca elatior no município de Gado Bravo, Paraíba. Note necrose dos linfócitos do centro germinativo secundário, caracterizado pela presença de núcleos picnóticos e cariorréticos. HE, obj.40x.

A inspeção da área de plantação de palma da propriedade revelou intensa infestação por uma planta herbácea, semelhante à planta fornecida para os bovinos. Essa planta foi identificada posteriormente como Portulaca elatior (tombamento $\mathrm{n}^{\circ} 22.276$ na UFPB).

\section{DISCUSSÃO}

O diagnóstico de intoxicação por Portulaca elatior neste surto foi baseado nos dados epidemiológicos, sinais clínicos, achados de necropsia e histopatológicos, além da presença da planta no conteúdo ruminal. 0 histórico do fornecimento exclusivo da planta no cocho após 10 horas de confinamento e jejum foram evidências circunstanciais fortes da intoxicação destes bovinos por P. elatior. Além disso, os sinais clínicos e os achados patológicos foram semelhantes aos descritos na intoxicação natural e experimental por esta mesma espécie de planta em caprinos (Galiza et al. 2011).

No presente surto foi observada uma morbidade de $57 \%$ e mortalidade de $28 \%$. A vaca que morreu tinha o maior porte entre as demais, era a líder do rebanho e segundo o proprietário somente permitia a aproximação da bezerra que também desenvolveu o grave quadro de intoxicação, sugerindo que ambas ingeriram maior quantidade planta. Porém, não foi possível determinar a quantidade de planta ingerida por cada bovino. Os casos de intoxicação por P. elatior em caprinos ocorreram também no Agreste da Paraíba, onde a planta cresce ao longo das margens das estradas e invade as pastagens. No rebanho de caprinos, foram acometidos os 16 animais que haviam sido introduzidos recentemente em uma área infestada pela planta e eram provenientes de outra região. Entre os 300 caprinos preexistentes na propriedade, foi acometido somente um caprino, sugerindo que o desconhecimento é o fator determinante para a ocorrência de casos de intoxicação (Galiza et al. 2011). Nos bovinos, não há relatos de intoxicação a pasto, porém a planta fornecida no cocho foi consumida to- talmente, demonstrando que é palatável para esta espécie, pelo menos quando os animais estão há algumas horas em jejum.

As lesões mais importantes consistiam de alterações circulatórias e degenerativas dos pré-estômagos, abomaso e intestinos. Histologicamente, os pré-estômagos apresentavam degeneração e necrose das células epiteliais. Estes achados devem ser diferenciados de outras condições que afetam os pré-estômagos de bovinos, principalmente acidose ruminal por carga excessiva de grãos e intoxicação por outras plantas tóxicas. 0 diagnóstico de acidose ruminal foi descartado, já que os bovinos não estavam ingerindo grãos ou outro alimento rico em carboidratos de rápida fermentação, principal causa de acidose ruminal em bovinos criados em sistema de confinamento (Brown et al. 2007). No nordeste do Brasil a intoxicação por P. elatior deve ser diferenciada da intoxicação por Stryphnodendron coriaceum e Enterolobium contortisiliquum, pois ambas também induzem distúrbios gastrointestinais. S. coriaceum causa atonia ruminal, perda de peso e morte após oito dias do início dos sinais clínicos (Tokarnia et al. 1991). E. contortisiliquum induz anorexia, diarreia e desidratação (Tokarnia et al. 1960), além de lesões hepáticas que resultam em fotossensibilização secundária (Olinda et al. 2015). Estas plantas não foram encontradas na propriedade do presente estudo.

Os tecidos linfoides apresentaram lesões de necrose das células linfoides. Lesões linfoides são descritas nos casos de intoxicações por Schultesia guianensis (Tokarnia et al. 1994), Riedeliella graciliflora (Riet-Correa et al. 2001), plantas do gênero Baccharis (Oliveira-Filho et al. 2011), Ricinus communis, Polygala klotzschii, (Tokarnia et al. 2012), e na intoxicação por Simarouba versicolor (Carvalho et al. 2013) em bovinos. Plantas do gênero Baccharis apresentam tricotecenos citotóxicos que interferem na síntese de proteínas das células em divisão dos órgãos linfoides (Rocha et al. 2005), culminando em apoptose e perda celular (Uzarski et al. 2003). A toxina ricina presente nas sementes de Ricinus communis é descrita como responsável pela apoptose nos centros germinativos do tecido linfoide e associado a essa toxina o choque pode contribuir na gênese da necrose do tecido linfoide. De Polygala klotzschii foi isolado a 5-metoxi-podofilotoxina, considerada como o princípio tóxico da planta (Tokarnia et al. 2012). Na espécie $P$. elatior foram encontrados altos níveis de oxalatos (Galiza et al. 2011), porém a ausência de cristais de oxalatos nos rins e sistema digestório dos bovinos do presente estudo e nos casos espontâneos e experimentais de intoxicação por essa planta em caprinos (Galiza et al. 2011), descartam o envolvimento de oxalatos na patogenia da doença.

Os achados clínico-patológicos da intoxicação por $P$. elatior diferem dos descritos na intoxicação por P. oleracea em ovinos. Enquanto P. elatior induz principalmente distúrbio gastrointestinal e morte após mais de 30 horas de sua ingestão, $P$. oleracea causa quadro de hipóxia e morte entre uma e quatro horas, devido a presença de nitratos e nitritos (Simões 2013). As lesões encontradas nos bovinos não foram compatíveis com as descritas nas intoxicações por plantas que contêm altos níveis de nitratos e nitritos. 0 princípio tóxico de P. elatior ainda não foi determinado. 


\section{CONCLUSÕES}

A planta herbácea Portulaca elatior causou intoxicação aguda em bovinos, que a receberam em estado fresco no cocho no período de seca.

Não há relatos de casos de intoxicação pelo consumo de P. elatior no pasto, porém a planta é ingerida naturalmente quando os animais passam por período de jejum.

Os produtores de bovinos do semiárido devem ser orientados a não fornecer a planta aos animais ou evitar que tenham acesso a áreas infestadas pela planta.

Estudos futuros deverão ser realizados com $P$. elatior para determinar a dose tóxica para bovinos, o princípio ativo da planta e o seu mecanismo na patogenia da intoxicação.

Agradecimentos.- Este trabalho foi realizado com apoio Instituto Nacional de Ciência e Tecnologia (INCT) para o estudo do Controle das Intoxicações por Plantas (CNPq Proc. 573534/2008-0).

\section{REFERÊNCIAS}

Brown C.C., Baker D.C. \& Barker I.K. 2007. Alimentary system, p.1-296. In: Maxie M.G. (Ed.), Jubb, Kennedy, and Palmer's Pathology of Domestic Animals. Vol.2 and 3. 5th ed. Elsevier Saunders, Philadelphia.

Carvalho N.M., Bacha F.B., Santos A.C., Carvalho A.Q., Faccin T.C., Pott A. \& Lemos R.A.A. 2013. Spontaneous and experimental intoxication of cattle by Simarouba versicolor A. St.-Hil. (Simaroubaceae). Toxicon 64:55-59.

Coelho A.A.O.P. \& Giulietti A.M. 2010. 0 gênero Portulaca L. (Portulacaceae) no Brasil. Acta Bot. Bras. 24:655-670.

CPRM 2005. Diagnóstico do Município de Gado Bravo. Serviço Geológico do Brasil Disponível em <http://www.cprm.gov.br/rehi/atlas/paraiba/ relatorios/GAD0079.pdf> Acesso em 10 ago. 2015.

Eggli U. \& Ford-Werntz D. 2002. Illustrated Handbook of Succulent Plants, Dicotyledons. Portulacaceae. Springer, New York, p.370-432.

Galiza G.J.N., Pimentel L.A., Oliveira D.M., Pierezan F., Dantas A.F.M., Medei- ros R.M.T. \& Riet-Correa F. 2011 Intoxicação por Portulaca elatior (Portulacaceae) em caprinos. Pesq. Vet. Bras. 31:465-470.

Legrand C.D. 1962. Las Especies Americanas de Portulaca. Mus. Hist. Nat. Montevideo 7:9-147.

Olinda R.G., Medeiros R.M.T., Dantas A.F.M., Lemos R.A.A. \& Riet-Correa F. 2015. Intoxicação por Enterolobium contortisiliquum em bovinos na região Nordeste do Brasil. Pesq. Vet. Bras. 35:44-48.

Oliveira-Filho J.C., Carmo P.M.S., Lucena R.B., Pierezan F. \& Barros C.S.L. 2011. Baccharis megapotamica var. weirii poisoning in water buffaloes (Bubalus bubalis). J. Vet. Diagn. Invest. 23:610-614.

Riet-Correa F., Górniak S.L., Haraguchi M. \& Dagli M.L.Z. 2001. Histological changes caused by experimental Riedeliella graciliflora (Leg. Papilionoideae) poisoning in cattle and laboratory animals. Pesq. Vet. Bras. 21:5-7.

Rocha O., Ansari K. \& Doohan F.M. 2005. Effects of trichothecene mycotoxins on eukaryotic cells: a review. Food Addit. Contam. 22:369-378.

Simões J.G. 2013. Intoxicação por Portulaca oleraceae L. em ovinos. Monografia de Conclusão de Curso, Centro de Saúde e Tecnologia Rural, Universidade Federal de Campina Grande, Patos, PB. 33p.

Silva D.M., Riet Correa F., Medeiros R.M.T. \& Oliveira O.F. 2006. Plantas tóxicas para ruminantes e eqüídeos no Seridó Ocidental e Oriental do Rio Grande do Norte. Pesq. Vet. Bras. 26:223-236.

Tokarnia C.H., Canella C.F.C. \& Döbereiner J. 1960. Intoxicação experimental pela fava da "timbaúba" Enterolobium contortisiliquum (Vell.) Morong. em bovinos. Arq. Inst. Biol. Anim., Rio de J., 3:73-81.

Tokarnia C.H., Peixoto P.V., Gava A. \& Döbereiner J. 1991. Intoxicação experimental por Stryphnodendron coriaceum (Leg. Mimosoideae) em bovinos. Pesq. Vet. Bras. 11:25-29.

Tokarnia C.H., Döbereiner J. \& Peixoto P.V. 1994. Aspectos clínicos-patológicos complementares da intoxicação por algumas plantas tóxicas brasileiras. Pesq. Vet. Bras. 14(4):111-122.

Tokarnia C.H., Brito M.F., Barbosa J.D., Peixoto P.V. \& Döbereiner J. 2012. Plantas Tóxicas do Brasil para Animais de Produção. 2aㅡ ed. Editora Helianthus, Rio de Janeiro. 586p.

Uzarski R.L., Islam Z. \& Pestka J.J. 2003. Potentiation of trichothecene-induced leukocyte cytotoxicity and apoptosis by TNF alpha and Fas activation 2. Chem. Biol. Interact. 146:105-119. 